\title{
Striving for social justice: understanding gender issues at the workplace in India
}

\begin{abstract}
BACKGROUND
Patriarchy dominates not only the mind-set and behavioural patterns of both males and females in India in general but also has a far-reaching impact on work culture as well as quality of work life. Indians not only suffer the archaic gender patterns but also are burdened with a unique system of caste that discriminates people based on their birth in a particular section of society. The government has made an effort to eradicate the adverse impacts of the caste system by making a unique reservation policy (a form of affirmative action) in work and education that tries to promote social justice.
\end{abstract}

\section{PARTICIPANTS AND PROCEDURE}

The present research study was conducted to assess the perception of public-sector employees of the diversity climate of their organizations (in terms of the diversity created by the affirmative action) and the psychological impact of this perception. Three hundred participants (all employed in public-sector organizations) were categorized into four groups, namely General Category Men, Reserved Category Men, General Category Women and Reserved Category Women. Participants in the reserved category were those who had directly benefitted from the affirmative action. All the participants were given questionnaires to assess perceived diversity climate, work-family conflict and alienation from work. Thirty percent of the participants were interviewed with semi-structured open-ended questions. Quantitative data were analysed using both descriptive and inferential (ANOVA) statistics.

\section{RESULTS}

The study's findings revealed that women in the two categories hold contrasting perceptions of their organisations' diversity climates. While among the four categories General Category Women hold the worst perception, Reserved Category Women hold the best. The former suffer from severe psychological consequences. Qualitative analysis via thematic analysis of individual interviews revealed themes that explain the findings of the study.

\section{CONCLUSIONS}

The findings demonstrate the importance of developing a work culture of inclusion rather than assimilation in the organisations adhering to a caste-based quota system, where differences between the categories and gender are recognised, valued and engaged. Different voices are understood as being legitimate and as opening up new vistas; they are heard and integrated in decision-making and problem-solving processes. They have an active role in shaping culture and fostering creativity and innovation and eventually in adding value to the company's performance, allowing people with multiple backgrounds, mindsets and ways of thinking to work effectively together and to perform to their highest potential in order to achieve organisational objectives based on sound principles. In such an environment different voices are respected and heard, diverse viewpoints, perspectives and approaches are valued, and everyone is encouraged to make a unique and meaningful contribution.

\section{KEY WORDS}

gender issues in India; Indian social norms; caste-based quota system; reverse discrimination

ORGANIZATION - University of Delhi, New Delhi, India

E: Manuscript preparation · F: Literature search · G: Funds collection

CORRESPONDING AUTHOR - Suparna Jain, Ph.D., A-53, Phase 1, Ashok Vihar, Delhi-110052, India, e-mail: suparna85@ gmail.com

TO CITE THIS ARTICLE - Jain, S., \& Bhardwaj, G. (2016). Striving for social justice: understanding gender issues at the workplace in India. Health Psychology Report, 4(3), 246-260. doi: 10.5114/hpr.2016.58004

RECEIVED 08.12.2015 · REVIEWED 03.01.2016 · ACCEPTED 07.02.2016 · PUBLISHED 04.03.2016 


\section{BACKGROUND}

The socio-cultural milieu of India is predominantly flavoured by notions of patriarchy. This has a deep impact on work culture and quality of work life for both women and men. The technology-driven $21^{\text {st }}$ century has brought modern norms and values such as wider acceptance of women in the mainstream workforce. However, traditional notions remain embedded in the intra-psychic space of individuals. There is a struggle for Indian women to maintain a balance between traditional and modern norms and values that drive their behaviour and shape their experiential perspectives (Chaudhuri \& Panigrahi, 2013).

Government policies for inclusion of the 'socially backward' and of women have resulted in a diverse workforce. The focus of the present work is to examine the impact of this diversity on gender issues at the workplace. The complexity of the question is increased by the uniqueness of the prevalent caste system that has led to social backwardness in sections of society, and the shadows of a patriarchal mind-set affecting the space for women in society, especially in the workforce.

The caste system is a major ingredient of culture in India, and it negatively affects a large segment of its population. Estimated to be over 2500 years old, the caste system has undergone many transformations, from the ancient Varna system to the contemporary fati system. The Varna system divided the population initially into four and later into five mutually exclusive, endogamous, hereditary and occupation-specific groups: the Brahmins, Kshatriyas, Vaisyas, Sudras and Ati-Sudras. The last two comprised all castes doing menial jobs, with the latter being considered "untouchables", in that even their presence was considered polluting and thus was to be avoided. The three higher varnas are often referred to as "caste Hindus" (upper caste Hindus) or as "twice born", since (the men of) these castes enter an initiation ceremony (the second birth) and are allowed to wear the sacred thread. Over the years as the economy and society grew more complex, this system metamorphosed into the fati system, with features similar to the Var$n a$ system, but with some differences. The number of jatis today is estimated to be between 2 and 3000 . Clearly, this division of castes/jatis corresponded to a rudimentary economy.

Thus, the Government of India constitutionally identifies certain groups as "socially backward" and classifies them as Scheduled Castes (SCs), Scheduled Tribes (STs) and Other Backward Classes (OBCs) (Government of India, 1950). It mandates a quota-based reservation in education and employment in proportion to the population for groups that fall within these classifications (Rana, 2008). While reservation for SCs and STs was provided since indepen- dence in 1947, reservation for OBCs was introduced only recently on $10^{\text {th }}$ April, 2008. The identification of the backward classes to be listed under one of these classifications is based on the commissions instituted by the then President of India. The first of these commissions was appointed in 1953, under the Chairmanship of Kalelkar. A second Backward Classes Commission was chaired by B. J. Mandal, which was installed in 1979.

The government's policy of quota-based reservation aims at equal opportunity and equal representation by all sections of society. At present, approximately $50 \%$ of positions in public sector jobs are reserved for the socially backward (Supreme Court of India, 1990).

Past research has shown that there are many controversies over affirmative action; one such concerns the case where a particular group is underrepresented in a job due to previous discrimination. To represent it equally in the job requires that during current hiring the members of this group are hired more than the other groups. This would surely reduce their under-representation caused due to previous inequality but would still create inequalities this time against current applicants of other groups. So, is it helping achieve social justice or rather creating injustice in itself? A second controversy is the demeaning of merit. The costs that are often cited due to affirmative action include the losses of efficiency that occur when less than best qualified applicants are chosen, as well as the hostility and suspicion of the bypassed candidates and the qualified co-workers.

This controversy is clearly demonstrated in a comprehensive investigation presented by Madeline E. Heilman in "Affirmative Action: Some Unintended Consequences for Working Women" (Heilman, 1994), which gives a picture of the negative consequences of the quota system. Heilman's experiments and analysis found that the quota system impacts a person's self view and has effects on work place attitudes and behaviour. She proposed that:

1. Impact on the self

- Preferentially selected candidates may face higher stress levels than those selected on a merit basis (Heilman, Lucas, \& Kaplow, 1990).

- Preferentially selected individuals rate the process as less fair than those selected on a merit basis.

- When using an affirmative action policy to select women for traditionally sex-typed jobs, preferential treatment can result in negative self-regard for the individual (Heilman, Simon, \& Repper, 1987). Thus, it is likely that women who are selected on the basis of sex, rather than merit, will invest less effort in task accomplishment, will be less likely to persevere when they encounter difficulty, and will choose easier tasks.

- Women who are hired under preferential treatment appear to devalue and resist hiring other women
Gender issues at the workplace in India 
when the preferential treatment results in undermining of their own confidence.

2. Work place attitudes and behaviour:

- The greater the role that affirmative action was believed to have played in a co-worker's hiring, the less likely qualifications were thought to have been an important factor, and the less competent the co-worker was thought to be, unless explicit information was provided to suggest otherwise.

- Inequity-based perceptions by others in the organization may result in lowered motivation in addition
Suparna Jain, Gopa Bhardwaj to negative reactions to the individual who is believed to have benefited undeservedly.

- When there was no mention of affirmative action, women hired for positions were rated lower in competence than men only when the job was strongly sex-typed. However, when linked to affirmative action, women were rated as less competent in both sex-typed and sex-neutral jobs, and were also rated as less competent than other women whose hiring was not associated with affirmative action.

In summary, Heilman illustrates that affirmative action results in a negative self-view for the benefiting individual who lacks self-confidence, an overall stigma of incompetence in the work place environment, and possible negative behaviours both from and toward those individuals hired as a result of affirmative action policies.

Another extensive study that illustrates the paradoxes involved in affirmative action suggested that the existence of affirmative action programmes may create or exacerbate negative perceptions of groups that benefit from these programs. To test this hypothesis, the authors presented 51 participants with a (fictitious) editorial describing a relatively unfamiliar immigrant group in a positive manner and manipulated whether the group was described as being able to benefit from affirmative action programmes. Participants then rated their perceptions of and attitudes toward the group. Participants also indicated their attitudes and thoughts about the group's immigration and their attitudes toward immigration in general. The results indicated that when affirmative action was mentioned, participants expressed less favourable perceptions of and attitudes toward the group and were less favourable toward immigration by the group. Interestingly, when affirmative action was mentioned, participants were also less favourable toward immigration in general. Overall, these findings indicate that the existence of affirmative action programmes can have far-reaching effects on attitudes toward groups (Maio \& Esses, 1998).

However, the opposing point of view is that preferential treatment encourages diversity in an organisation, which can lead to improved overall general welfare of the society. The members of many racial, sexual and ethnic groups identify strongly with the fortunes and accomplishments of other group mem- bers; given this mutual identification, increasing diversity will benefit not only those group members who actually gain a prestigious, well-paying position, but also the many others who take pride and pleasure in their success. They pave the path for the coming generations of their groups to take up similar or even better jobs in the future.

In addition, it can be argued that working closely with members of unfamiliar groups breaks down barriers and disrupts stereotypes, and that increasing racial, sexual and ethnic diversity will therefore increase overall well-being by fostering understanding and harmony.

The increasing racial, sexual and ethnic diversity would also advance the academic enterprise. Neil Rudenstine, the former president of Harvard University, expressed the idea by saying "A diverse educational environment challenges students to explore ideas and arguments at a deeper level - to see issues from various sides, to rethink their own premises, to achieve the kind of understanding that comes only from testing their own hypotheses against those of people with other views". Thus, the reservation policy has been a topic of discussion for a long time now, as some people support its benefits and others believe that the paradoxes leading to injustice outweigh the benefits.

In India as well the reservation policy has generated a notion of reverse discrimination. It seems to have resulted in different socio-psychological states for groups within the workforce. It might be affecting the prevalent gender issues indirectly, but profoundly. Plurality of membership and plurality of interests in the workforce play a significant role in deciphering the meaning of social justice and gender issues. It is believed that there is a strong need to review and resituate these issues for a stronger and more productive workforce.

\section{DIVERSITY IN THE WORKPLACE}

Increasing participation of currently underrepresented groups in the workforce is a desirable trend towards development of the country (Full Text of Sonia Gandhi, Congress President, 2014). As is true with increasing women's participation, increasing participation of 'socially backward groups' is central to their empowerment as well (Persson, 2009). However, the latter's increasing participation has been facilitated by the government's policy for affirmative action that enforces mandatory reservation for underserved castes and classes in public sector workplaces (Article 16, Section 4, Constitution of India, 1950).

The introduction of the quota system saw significant resistance from groups that were not classified as socially backward. Questions of reverse discrimination and oversight of merit were raised and are still heavily debated. The reservation policy led to a tre- 
mendous, and rather sudden and enforced, change in the diversity climate in public sector workplaces. The diversity in social groups came with diversity in professional backgrounds, economic status, and traditional and cultural practices (Mandhana, 2012).

The psychological consequences of the increasing diversity affect employees of various categories and gender. The employees' perception of the diversity created by the policy as well as the policy as a whole is important to gauge their existential realities at work and outside it. Gender dynamics are evident when the psychological consequences are separately studied for men and women.

Thus, the present study examines the perception among male and female employees of the increasing diversity due to the reservation policy along with an aim to understand the present gender dynamics in the workforce and the effects of current changes on it. The psychological consequences of the perception of these employees have been studied in terms of experienced alienation from work and extent of experienced conflict between work and family. These aspects as psychological consequences were chosen as they are integrally related to gender and social justice issues, especially in a country like India which is undergoing a very fast modernization process and also struggles with issues related to equality and justice.

\section{WORK-FAMILY CONFLICT AND WORK ALIENATION: PSYCHOLOGICAL CONSEQUENCES OF DIVERSITY PERCEPTION}

Balancing work and family has become an important management issue. From research it appears that employees nowadays seem to value the quality of life more than the amount of remuneration they receive (Vloeberghs, 2002). Recent studies have shown that people want to have more control over their work and accord more meaning to their non-work life. As a result, according to Chalofsky (2003), the best employers are not great because of their perks and benefits, but because of their organisational cultures and policies that promote meaningful work and a nurturing, supportive workplace. In general the subjective quality of the experiences an individual has in both work and family roles is a critical determinant of psychological well-being (Frone, Russell, \& Cooper, 1992). For example, work experienced as demanding or not rewarding may increase the chances of work-family strain, whereas work that is more rewarding may reduce the chances of strain. In addition, work and family experience may have reciprocal effects so that perceptions and behaviour in one role are affected to some degree by experiences in the other (Williams \& Alliger, 1994).

Past research on the topic has solely focused on differing causes and consequences of work-family conflict. The present research rather than merely pointing out the causes and consequences aimed to evaluate the impact of perception of work place diversity on experienced work-family conflict. The researcher was of the opinion that work-family conflict would increase if the employees did not have a good perception of the diversity climate of their organisation. Employees who would feel discriminated against, for instance, meritorious employees who believe that the reservation policy gives opportunities to employees while neglecting the merit, would surely find it difficult to maintain their calm both in the work and family setting.

A dissatisfying environment at work can lead to displacement of negative emotions to the family setting. And thus, due to these negative emotions a person may not be able to do justice to the other important roles in his/her life such as being a good parent or a good spouse.

Another consequence of perception of diversity climate was studied in terms of experience of work alienation. Various research studies show that the rare phenomenon of alienation is affecting more and more professionals and managers every day. Highly successful male executives in mid life report doubts about the meaning of success, considerable self doubt, disquiet over their careers (despite their success) and great value conflict (Henry, 1961). A survey of several thousand managers who attended courses run by a well-known training association reported great degrees of personal and social alienation; that is, their careers were no longer meeting their personal needs and they felt considerable alienation from the organisations for which they worked (Tarnowieski, 1973).

Similarly, interviews of successful young executives and their wives revealed great feelings of stress, a loss of personal alertness, and an increasing sense of meaninglessness in everyday activities (Bartoleme, 1972). A study of one thousand middle aged professionals and managers found that approximately $80 \%$ went through periods of intense frustration as early as their late 30 s and that $15 \%$ never really recovered from this period (Schultz, 1974).

Previous research has pinpointed major causes of work alienation. For instance, an extensive study was done on employees who had received their MBA from a well-known institute and had been working for a minimum of two months in an organisation. They found "loss of affiliative satisfaction" to be the most significant cause of alienation among the sample. This cause of alienation points to the achievement versus affiliation conflict in contemporary life; this missing affiliation could be at the workplace or at the family level, leading to work-family conflict. The second significant causal factor for alienation was found to be "disconfirmed expectations". Intrinsic to the concept of expectancy disconfirmation in the work setting is
Gender issues at the workplace in India 
Suparna Jain, Gopa Bhardwaj the notion of equity. Violation of the belief of "fair treatment" is proposed to be a major source of alienation. "Contradictory role demands" appeared to have some significance as a factor in alienation but not as great as the previous two factors. This factor is a cognitive state which occurs when an individual realizes that some of the demands on him are contradictory and always will be, regardless of anything he may do. As a result he must inevitably sacrifice some of his personal desires, in terms of both individual career needs and interpersonal relationships. Another causal factor which did not emerge as a significant factor in the study, but has been repeatedly found to be a major cause of alienation is "sense of external control (Powerlessness)". It is a cognitive realization that one has been doing things because one has been told to by others. The perception that one has been manipulated and controlled leads to both personal and social alienation (Korman \& Wittig-Berman, 1980).

In the present study, Seeman's (1959, 1967, 1972) perspective on work alienation has been adopted to understand work alienation with respect to perception of employees of the diversity climate of their organisation.

The researcher believes that dissatisfaction with various aspects of the diversity climate of the organisation such as organisational fairness, organisational inclusiveness, etc., can have a negative impact on employees' motivation and efficiency at work. This motivation and efficiency would decrease as a result of employees' experience of work alienation.

Work alienation, as a feeling of detachment from work, may develop as a result of powerlessness that employees may feel due to the legalized reservation policy, meaninglessness in work that they may experience due to quotas in promotion, normlessness they may perceive due to lower standards of entrance cut-off for the reserved category and social isolation they may find themselves in due to lack of control of the situation of all others also who belong to their fate.

Thus, according to the researcher it is very important to study the impact of the diversity climate on the employees' output. Otherwise the reservation policy rather than helping the society, organisation and country to progress may lead to deterioration in the present outputs of the employees, organisation and the country.

For the purpose of the study, the employees experiencing diversity were divided into four groups, namely, General Category Men (GCM), General Category Women (GCW), Reserved Category Men (RCM) and Reserved Category Women (RCW), elaborated under the sample head.

Based on the review, five hypotheses were developed. The first hypothesis was that there would be a significant difference between the four groups, based on their perception of the diversity climate of their organisations. It was expected that General Category employees would have worse perception as compared to the Reserved Category. Also among the general category, female employees would have poorer perception. The second hypothesis was that there would be a significant difference between the four groups based on differing genders and reservation categories in their extent of experienced work alienation. It was expected that General Category employees, specifically women, would suffer from greater work alienation. The rationale behind the predictions made in hypotheses 1 and 2 is that there has been quite an outrage among the unreserved category of employees against the reservation policy as stated in an earlier reference by Mandhana (2012). Also female unreserved employees are expected to suffer more because women already have a disadvantage in the Indian patriarchal society, as clearly reported in the Global Gender Gap Report by the World Economic Forum (2013), and the reservation policy would add to this disadvantage. The third hypothesis was that there would be a significant difference between the four groups based on differing genders and reservation categories in their extent of experienced work-family conflict. Female employees specifically from the reserved category are expected to suffer from it the most. Research reveals that they are under severe constraints of patriarchy both at home and work. For example, at home they are expected to give priority to household chores, but at the same time the new world of work poses its own challenges (Rajadhyaksha \& Smita, 2004). The fourth hypothesis was that the negative perception of the diversity climate would act as a predictor for experience of work alienation across the groups. It has been found through research that employees who believe that the rules and the power structure of the workplace are unfair attribute their lower status externally to an unjust system. The workers become disobedient and express high levels of alienation and job dissatisfaction (Cable, 1988). The fifth hypothesis was that work alienation is a moderator variable; employees experiencing higher work alienation would experience higher work-family conflict across the groups. Previous research has revealed that job-related stressors (provoking work alienation) such as time constraints, incompatible work role expectations, lack of social support at work and lack of instrumental support at work are highly common causes of work-family conflict among employees (Luk \& Shaffer, 2005).

The overall findings of the research were placed around the model "Alienation as a Social Process" developed by James E. Twining in 1980.

Twining divided his model into three phases. The first phase explains how an individual develops a sense of self in an organisational setup. The second phase deals with the way the developed sense of self 
leads to an overall positive or negative experience of the individual at work, negative experience leading to various types of work alienation. The third phase involves the response to the employee at work and outside based on his/her experience in the second phase.

In the present study, the first phase of defining self in correspondence to the workplace is mediated by the diversity created by the quota system. All the employees of the public/government sector know the reason behind the affirmative action. They all understand that there has been a historical reason: the caste-based discrimination, due to which the quota system was put in place.

The second phase focuses on the resultant positive or negative definition of the overall situation, which in the present study is the extent of work alienation being experienced by the four groups differentially as a consequence of their perception of the diversity climate as well as the quota system as a whole.

In the third phase the level of work alienation experienced by various groups would impact their work as well as personal life, which in the present study was assessed through the extent of work-family conflict.

\section{PARTICIPANTS AND PROCEDURE}

A mixed method was employed comprising both quantitative and qualitative methods. For quantitative data collection, three questionnaires were administered to the entire sample of 300 participants.

A semi-structured situational interview (Appen$\operatorname{dix}$ A) was also conducted on $30 \%$ of the participants $(n=90)$. All participants were given an open-ended question pertaining to the participants' overall perception of the reservation policy, supplemented by a critical incident technique in which the respondents were asked to narrate critical and relevant experiences.

\section{PARTICIPANTS}

The sample comprised 300 participant public sector employees with a mean age of 37 who were chosen at random from multiple matched organisations. The participants were classified into four groups on the basis of gender (women or men) and official social status (reserved or general). Employees belonging to scheduled castes, scheduled tribes or other backward classes were classified as reserved, while all the rest were classified as general. Forty percent of the participants $(n=123)$ were in General Category Men (GCM), 30\% ( $n=90)$ were in General Category Women (GCW), 22\% ( $n=66)$ were in Reserved Category Men $(\mathrm{RCM})$ and the remaining $7 \%(n=21)$ were in Reserved Category Women (RCW).

\section{MEASURES}

Perceived Diversity Climate Questionnaire. This 11-item questionnaire was developed by Surendra Kumar Sia (2007) as an adaptation of the Diversity Perception Scale (DPS) developed by Barak, Cherin and Berkman (1998). The adapted questionnaire broadly focused on the extent to which an employee perceives the plans, policies and programmes of the organisation to be fair towards him/her, the feelings or perceptions of the individual about the initiatives taken or interests shown by the organisation towards integration or accommodation of employees like him/ her with the other employees belonging to various groups, and also how the respondent values diversity in the organisational context. Examples of representative items included are: "I feel I have been treated differently here because of my religion/sex/reservation category/mother tongue, etc.", "Management here encourages those who give support to the minority or female employees", "Employees from a different background make the environment uncomfortable". The response pattern for the questionnaire is that of a 5-point Likert type scale, i.e. 1 for strongly agree and 5 for strongly disagree. Cronbach's $\alpha$ for the questionnaire is .71.

Work Interference with Family and Family Interference with Work Questionnaire. This measure was developed by Gutek, Searle and Klepa (1991) and later revised by Carlson and Perrewe (1999). In the questionnaire the responses are obtained using a 5-point Likert type scale where 1 for strongly agree and 5 for strongly disagree. A higher score indicates lower work-family conflict. The total number of items on the scale is 12. Examples of representative items included are: "After work, I come home too tired to do some of the things I would like to do", "My personal life takes up time that I would like to spend at work". Cronbach's $\alpha$ of the questionnaire computed with the Indian population is 85 .

Alienation from Work Questionnaire. This 30-item questionnaire was developed by Shephard (1972). Using Seeman's (1959) analysis, he incorporated 5 aspects of alienation in his questionnaire, namely, Powerlessness, Meaninglessness, Normlessness, Instrumental work orientation and Self-evaluative involvement. A high score on the scale indicates low alienation. Examples of representative items included are: "To what extent can you vary the steps involved in doing your job?" (Powerlessness), "To what extent do you know how your job fits into the total work organisation?" (Meaninglessness), "To what extent do you feel that people who get ahead in the company deserve it?" (Normlessness), "Your job is something you do to earn a living - most of your real interests are centred outside your job" (Instrumental work orientation) and "To you your work is only a small part of who you are" (Self-evaluative involve-
Gender issues at the workplace in India 
ment). Cronbach's $\alpha$ of the questionnaire computed with the Indian population is .79.

\section{PROCEDURE}

A mixed methodology was employed. Three questionnaires were selected for the quantitative research and an interview schedule was developed for qualitative data collection.

All the public sector organisations having their Suparna Jain, Gopa Bhardwaj

head office in Delhi were listed; out of them 10 organisations were selected at random using the table of random numbers. Permission was sought from these 10 public and government sector organisations for data collection. However, only 5 out of 10 organisations agreed due to the sensitivity of the topic. Later, these five organisations were requested to provide a list of their managerial level employees with their category status. Using the lists of employees, again random sampling was carried out with the aim of collecting data from 100 employees from each organisation. The percentage representation of the four groups under study was based on the ratio of the employees in each organisation, i.e. if an organisation had 15\% representation of Reserved Category Women, then in the sample of 100 the data were collected from 15 Reserved Category Women from that particular organisation. All the respondents were assured of the confidentiality of the responses. They were told that the study was purely for academic purposes and thus would not affect their job security. Even then a few disagreed to participate due to the sensitivity of the topic. But many others were excited to talk about the topic, as they found it to be a platform to vent their anxieties related to the reservation system.

Initially 35 questionnaires were administered as part of the pilot study. As two of the questionnaires were developed by foreign authors, their reliability was examined on the Indian population using Cronbach's $\alpha$. Alongside the pilot run, direct feedback was also sought from the participants about the semantics, difficulty level etc. of the questionnaires.

During quantitative data collection, each participant was asked if they would like to be interviewed about the topic. The ones who showed interest were contacted when three quarters of the sample was completed, and the interview process began. On average each interview took one and a half hours. During the interview the questions were asked from the semi-structured interview schedule and the participants were also probed to narrate their personal experiences. The interview was conducted in the organisation itself during the working hours with the permission of the management. Individual participants each received a pen given by the researcher. Also once the data were analysed, a copy of the find- ings was presented to each organisation that cooperated in data collection.

\section{RESULTS}

To analyse Hypotheses 1, 2 and 3, a two-way ANOVA [2 (Category: General/Reserved) × 2 (Gender)] was employed. The dependent variables were perception of diversity climate, work alienation and work-family conflict.

Multiple correlations were computed to analyse the relationship between perception of diversity climate and work-family conflict as well as work alienation. Step-wise regression was applied to further understand the significant correlations, to assess Hypothesis 4 and 5. Qualitative data were incorporated to gain an in-depth insight of the quantitative results obtained. For qualitative data thematic analysis was employed.

\section{PERCEPTION OF DIVERSITY CLIMATE}

The findings revealed a significant interaction effect of gender $\times$ category with regard to perception of the diversity climate with $F(1,299)=8.68, p=.003$ (Table 1). Among all groups, participants in GCW $(M=37.57, S D=0.49)$ and those in RCM $(M=37.24$, $S D=0.56)$ were observed to have the most negative perception of the diversity climate, whereas participants in RCW $(M=40.48, S D=1.01)$ were observed to have the most positive perception (Table 2), partially confirming Hypothesis 1.

\section{WORK ALIENATION}

For analysis of work alienation; the findings revealed the main effect of category with $F(1,299)=9.31$, $p=.002$ (Table 1). Participants from the reserved categories (RCM: $M=100.60, S D=1.48$; RCW: $M=100.90, S D=2.63)$ irrespective of their gender suffered from lower work alienation than participants from general categories (GCM: $M=94.72$, $S D=1.08$; GCW: $M=96.27, S D=1.22)$, thus partially confirming Hypothesis 2.

\section{WORK-FAMILY CONFLICT}

The findings revealed a main effect of gender $(F(1,299)=6.76, p=.010)$ and a main effect of category $(F(1,299)=4.26, p=.040)$. As shown in Table 2 , the mean values show that participants in the reserved category (RCM: $M=43.28, S D=0.85$; RCW: $M=40.90, S D=1.50$ ) suffered more work-family conflict as compared to the General Category employees (GCM: $M=43.57, S D=0.62$; GCW: $M=42.64$, 
$S D=0.73)$. The findings also revealed that male and female participants, irrespective of their category, differed significantly in their experienced work-family conflict. Compared to men, women suffered from higher work-family conflict.

With significant multiple correlations between the three variables (Table 3), regression analysis was employed to further understand the direction of impact between variables.

Poor perception of diversity climate was found to lead to work alienation for three out of four groups (GCM, GCW and RCM), hence partially confirming Hypothesis 4. The results of regression for GCM indicated $R^{2}=.15, F=4.12, p=.045$. It was found that poor perception of diversity climate significantly predicted work alienation $(\beta=.18, p=.045)$. Likewise, the result of regression for GCW indicated
$R^{2}=.25, F=5.29, p=.024$. It was found that poor perception of the diversity climate significantly predicted work alienation for GCW $(\beta=.24, p=.024)$ and the results of regression for RCM indicated $R^{2}=.48$, $F=3.98, p=.050$. It was found that poor perception of the diversity climate significantly predicted work alienation for $\operatorname{RCM}(\beta=.24, p=.024)$.

Experience of work alienation was found to lead to work-family conflict among the same three out of four groups, hence partially confirming Hypothesis 5. The result of regression for GCM indicated $R^{2}=.05, F=12.26, p<.001$ with a finding that experienced work alienation significantly predicted work-family conflict $(\beta=.30, p<.001)$ and work-family conflict also predicted work alienation $(\beta=.30$, $p<.001)$, displaying a bi-directional relationship between the two variables. The result of regres-

Table 1

Analysis of two-way ANOVA

\begin{tabular}{lcccc}
\hline Source & $D f$ & Mean square & $F$ & $p$ \\
\hline Perceived diversity climate & 1 & & & .196 \\
Gender & 1 & 13.13 & 0.61 & .434 \\
Category & 1 & 185.67 & 8.68 & .003 \\
Gender x Category & 300 & & & .598 \\
Total & & & & .002 \\
Work alienation & 1 & 40.51 & 0.28 & .710 \\
Gender & 1 & 1354.52 & 9.31 & 0.14 \\
Category & 1 & 20.16 & & .010 \\
Gender $\times$ Category & 300 & & & .040 \\
Total & & & 6.76 & .371 \\
Work-family conflict & 1 & 79.90 & 4.26 & \\
Gender & 1 & 50.37 & 0.80 & \\
Category & 1 & 9.48 & & \\
Gender $\times$ Category & 300 & & & \\
Total & & & & \\
\hline
\end{tabular}

Table 2

Mean and standard deviation of the four groups for perceived diversity climate, work alienation and work-family conflict

\begin{tabular}{lrrrrrrrr}
\hline \multirow{2}{*}{ Variables } & \multicolumn{3}{c}{ General Category } & \multicolumn{3}{c}{ Reserved Category } \\
\cline { 2 - 9 } & \multicolumn{2}{c}{ Men (123) } & Women (90) & \multicolumn{1}{c}{ Men (66) } & \multicolumn{2}{c}{ Women (21) } \\
\cline { 2 - 9 } & $M$ & $S D$ & $M$ & $S D$ & $M$ & $S D$ & $M$ & $S D$ \\
\hline Perception of diversity climate & 38.67 & 0.42 & 37.57 & 0.49 & 37.24 & 0.56 & 40.48 & 1.01 \\
Work alienation & 94.72 & 1.08 & 96.27 & 1.22 & 100.60 & 1.48 & 100.90 & 2.63 \\
Work-family conflict & 43.57 & 0.62 & 42.64 & 0.73 & 43.28 & 0.85 & 40.90 & 1.50 \\
\hline
\end{tabular}


Table 3

Multiple correlations between the three variables

\begin{tabular}{lccc}
\hline & Perceived diversity climate & Work-family conflict & Work alienation \\
\hline Perceived diversity climate & 1 & \\
Work-family conflict & $.205^{* *}$ & 1 & $.152^{* *}$ \\
Work alienation & $.139^{*}$ & 1 \\
\hline Note. ${ }^{*}$ Correlation is significant at .05 level $\left(2\right.$-tailed); ${ }^{* *}$ Correlation is significant at .01 level (2-tailed)
\end{tabular}

Suparna Jain, Gopa Bhardwaj

Table 4

Themes regarding perception of quota system and diversity climate

\begin{tabular}{|c|c|c|c|}
\hline $\mathrm{RCM}$ & $\mathrm{RCW}$ & GCM & GCW \\
\hline $\begin{array}{c}\text { Damaging disparities } \\
\text { between General and } \\
\text { Reserved Category } \\
\text { employees }\end{array}$ & $\begin{array}{c}\text { Damaging Disparities } \\
\text { between General and } \\
\text { Reserved Category } \\
\text { employees }\end{array}$ & $\begin{array}{l}\text { Inefficiency of RC } \\
\text { employees }\end{array}$ & $\begin{array}{c}\text { Poor personal efficiency } \\
\text { of RC employees }\end{array}$ \\
\hline $\begin{array}{c}\text { Poor self-perception of } \\
\text { Reserved Category (RC) } \\
\text { employees }\end{array}$ & $\begin{array}{l}\text { Personal growth of RC } \\
\text { from quota system }\end{array}$ & $\begin{array}{c}\text { Learned helplessness } \\
\text { of RC }\end{array}$ & $\begin{array}{l}\text { Poor competency } \\
\text { utilization by RC }\end{array}$ \\
\hline $\begin{array}{l}\text { Feeling of inefficiency } \\
\text { by RC }\end{array}$ & & $\begin{array}{c}\text { Lack of organisational } \\
\text { efforts to train RC }\end{array}$ & $\begin{array}{c}\text { Indulgence in unethical } \\
\text { activities by RC }\end{array}$ \\
\hline $\begin{array}{l}\text { Facing stereotypes/ } \\
\text { biases by RC }\end{array}$ & & $\begin{array}{l}\text { Insecurity of their own } \\
\text { future }\end{array}$ & $\begin{array}{l}\text { Insecurity of their } \\
\text { children's future }\end{array}$ \\
\hline $\mathrm{RC}$ being targeted & & $\begin{array}{c}\text { Irrational legal support } \\
\text { to RC }\end{array}$ & $\begin{array}{l}\text { Immediate removal of } \\
\text { quota policy }\end{array}$ \\
\hline $\begin{array}{c}\text { Poor organisational ef- } \\
\text { forts to provide training } \\
\text { to RC }\end{array}$ & & & \\
\hline
\end{tabular}

sion for GCF indicated $R^{2}=.06, F=18.73, p<.001$, with a finding that experienced work alienation significantly predicted work-family conflict $(\beta=.42$, $p<.001)$ among them as well. The result of regression for RCM indicated $R^{2}=.07, F=10.36, p=.002$, with a finding that experienced work alienation significantly predicted work-family conflict $(\beta=.37$, $p=.002$ ) among them.

To analyse the quantitative findings in depth, the responses to the semi-structured interview were thematically analysed (Table 4). Through the qualitative findings the reasons behind the poor perception of various groups of the diversity climate could be deciphered and have been elaborated in the discussion that follows. The data supported Hypothesis 1.

\section{DISCUSSION}

The observed perception of the diversity climate does not reveal that the reservation policy is able to improve the conditions of social discrimination within the workforce.
For a deeper understanding of social justice and gender justice, we need to understand the level and type of alienation these groups experience as well as what kind of work-family conflict they are undergoing. For this purpose an analysis has been done using Twining's model (1980).

Results from regression analysis support the second phase of Twining's model as it has been found that the various groups suffer from various intensities of work alienation as a result of their poor perception of the policy and its implementation (Hypothesis 4).

In the third phase the work alienation experienced by various groups further leads to work-family conflict, as revealed by the regression analysis results (Hypothesis 5).

We now web our findings around the three phases for all the four groups separately. A group-wise understanding of how diversity perception leads to work alienation and work-family conflict is presented below.

General Category Men. Beginning with the first group, General Category Men (GCM), their overall perception of the diversity climate of their organisations is neither too positive nor too negative when 
compared with the other three groups under study. But when qualitatively analysed, it is found that although their position among the four groups may be of a neutral stance towards the diversity climate, they are of a view that the quota system requires major revamping. Thus, their present perception of the diversity climate is not positive.

They suffer from a high level of work alienation (Table 1). Their perception of the diversity climate is a major reason for their experience of work alienation. Thus, according to the model, they negatively define the present situation at the workplace in terms of the quota system.

This leads to the experience of "partial alienation" amongst them, i.e. work has become intrinsically meaningless for them but is still producing some positive gain in reference to the larger social setting. This indicates that they are working for the sake of money, status and need of fulfilment, but for them the intrinsic value of work has been and is diminishing.

This extent of work alienation is making them seek an alternative focus in order to re-establish a sense of control over activities and a positive definition of self. And to achieve that they have started focussing and spending more time outside work, especially with the family. This is leading to mild but some extent of work-family conflict among them. Because they are trying to find a positive sense of self in the family in order to overcome work alienation and specifically meaninglessness at the workplace, at times they feel their family is interfering with their job responsibilities.

This confused state of whether the family is helping them overcome or is creating further hindrance in their work is creating additional stress, intensifying the alienation for them. Thus, both work alienation and work-family conflict have a bi-directional relationship. But both are a consequence of the poor perception of the diversity climate of their organisation held by GCM.

General Category Women. Moving on to the second group, General Category Women (GCW), their overall perception of the diversity climate is poor. They feel like a secondary citizen of the organisation despite being more qualified than the reserved category. They believe that they are not given due credit for their qualifications, maybe because they are women. Also most of them feel threatened by the present quota system and opt for its total removal. They also worry about their children's future if the policy continues in the coming years.

According to Twining's model, this poor perception of diversity leads them to define their sense of self in a negative way in the present work scenario.

Consequently, as revealed in the regression values, it is leading to a high level of work alienation amongst them. As revealed in the interviews, they also feel powerless in the organisation due to the quo- ta system. Thus, they suffer from "fundamental work alienation" in which they experience a loss of control and meaning at work. They acknowledge separateness between themselves and their work without the motivational purpose of the external gain. Thus, they suffer from more intense work alienation as compared to the GCM, as the GCW are not even able to focus on work for extrinsic gains such as money, status, etc.

In turn, this high level of experienced work alienation leads to withdrawal from social situations for some and social isolation and self-estrangement for others, as denoted in the third phase of the model. Many of the GCW mentally withdraw from the workplace in order to establish new relations which offer an opportunity for control and meaning. But many others who are experiencing more intensified alienation are experiencing social isolation. It impacts their relation with their job, relations they hold with other employees and even their social relationships in other realms of life. This is why, as apparent in the regression values, they suffer from high work-family conflict.

Fundamental work alienation leads to intense work-family conflict. As they are unhappy at the workplace due to poor perception of the diversity climate, they are not able to focus well on their family roles. In addition, as they are not fulfilling their family roles it in turn leads to grave dissatisfaction at work.

They have got stuck in a vicious circle where their poor perception of the diversity climate is leading to fundamental work alienation in them, which in turn is hampering their performance both at work and family levels. The hampered family role increases their difficulty in focussing well on the work role.

Thus, for the present group work alienation is a mediating variable between the perceived diversity climate and work-family conflict. Work alienation is a direct consequence of poor perception of diversity that further leads to work-family conflict.

Reserved Category Men. The third group under study is Reserved Category Men (RCM). They have the worst perception of the diversity climate in comparison to the other three groups (Tables 1 and 2). Although happy to be part of the workforce, they experience name calling and humiliation and feel inferior to the general category. They hold a neutral personal value toward diversity, few being uncomfortable as they believe that they are too different from others based on educational and economic background and others accepting diversity as it is due to an empowering policy of the quota system.

But as repeatedly expressed in the interviews, their perception of the organisations' policies of implementing fairness and inclusiveness in the organisation is very poor. They feel biased against sometimes directly during performance appraisals and at other times indirectly in the ways co-employees mock and talk about the quota policy.
Gender issues at the workplace in India 
Suparna Jain, Gopa Bhardwaj
Presently they are not facing a very high extent of work alienation, as their experience is lower than the general category (Table 2). But still they are not free from the experience of alienation.

Thus, again according to the model, similar to the previous two groups, RCM also have a negative view of the diversity climate of their organisations. It leads to the suffering of 'partial alienation'. However, as revealed in qualitative data, they are unable to meet the norms of the organisations such as work procedures, policies, rules, etc., because they are still trying to adjust to the workplace and fighting hard to establish their place in the organisation where they face many biases and instances of humiliation.

This partial alienation further leads to work-family conflict. As they have not been able to settle well in the organisation yet, they take this frustration back home and at the same time they have additional family responsibilities due to migration to cities.

However, the balance between work and family is dwindling, mainly because they are not happy with the organisations not taking any steps towards making the workplace a fair place to be. They want to attain a respectable status in the organisation, which is still lacking.

Thus, overall it could be inferred that RCM's poor perception of the fairness of the policies and lack of inclusiveness efforts of the organisation to make them comfortable in the world of work leads to partial work alienation in them which in turn leads to work-family conflict.

Reserved Category Women. The fourth group comprises Reserved Category Women (RCW). They have the best perception of the diversity climate of their organisations in comparison to the other groups under study. This does not imply that they have an optimum perception, but it does imply that they are less dissatisfied with the diversity around them created through the quota system.

Based on the responses during the interview, $\mathrm{RCW}$ hold a slightly poor perception of the inclusiveness efforts of the organisation. They also revealed that often they do not let others at the work place know that they belong to the reserved category and they also do not let their children reveal the truth. This shows that somewhere they believe that reserved category people do go through various biases and humiliations in and outside the organisations.

But in the present research most of them revealed a positive perception of the diversity climate of their organisations, maybe because they are so happy to get the job that they are neglecting any signs of discomfort on their part or, as many said that they have not revealed the truth of their category to the co-workers, they are not being biased against.

Thus, according to Twining's model, this group defines their sense of self positively in today's world of work where there is so much diversity due to the quota system. Due to this positive definition they have been able to substantially integrate themselves in the workplace.

However, based on qualitative analysis it could be said that they are enjoying their work life not because they are getting intrinsically enriched by their participation at work but rather because after long years of subjugation they have got an opportunity to come out of their homes, become a part of the workforce and earn a living.

Additionally, RCW are also suffering from high levels of work-family conflict, but it is not a consequence of any of the two variables of the study. Despite holding a positive sense of self at work and suffering from minimal work alienation, they suffer from work-family conflict due to some other factors.

The reasons for the suffering could be that for a long time RCW have performed their traditional role of being a homemaker. Thus, it is a major shift in roles for them as well as for their families. Now because they have to come to the workplace, they have to compromise with the time spent with their families, which leads to work-family conflict. At the same time, as the organisations give them challenging tasks and expect them to perform, they are not able to meet the expectations as they still focus more on their family roles.

Thus, we could say that RCW are the ones with the best perception of the diversity climate and least experience of work alienation among the four groups. They are the only ones who have been able to adjust well to the diversity created by the quota system. However, as discussed above many have not disclosed their true identities to the co-workers, and thus it could not be said until when they would hold a positive perception in the real scenario of the work place today, because lies have a short life.

\section{IMPLICATIONS OF THE STUDY}

Although diversity in all forms is beneficial for any organization, it needs to be managed proactively. The policy implementation is impacting the state of social justice in India, but at the same time having negative implications for the Indian workforce at large. Unless the mindset is changed collectively, the quest for justice will not end. The empirical data and the social background analysis both indicate a similar pattern in terms of thought and its behavioural implications.

There is a need for bringing in a culture of inclusion in the organisations adhering to the caste-based quota system, where differences between the categories and gender are recognised, valued and engaged. Different voices are understood as being legitimate and as opening up new vistas; they are heard and integrated in decision-making and problem-solving processes. They have an active role in shaping culture 
and fostering creativity and innovation and eventually in adding value to the company's performance, allowing people with multiple backgrounds, mindsets and ways of thinking to work effectively together and to perform to their highest potential in order to achieve organisational objectives based on sound principles. In such an environment different voices are respected and heard, diverse viewpoints, perspectives and approaches are valued, and everyone is encouraged to make a unique and meaningful contribution.

Inspired by the work of Cox and Beale (1997), who discuss the process of learning to effectively deal with diversity, and Kotter's model of leading change (1996), Pless and Maak (2004) focussed on four essential transformation stages for building a culture of inclusion (depicted in Figure 1).
Thus, the realization of any potential benefit inherent in a diverse workforce requires an integrative approach to diversity starting with the definition of a framework of inclusion built upon principles of recognition, mutual understanding, standpoint plurality and mutual enabling, trust and integrity that allows for the integration of different and multiple voices into the organizational discourse. An important part of the process is a re-examination of underlying and rarely questioned assumptions which interfere with inclusiveness. Against this backdrop, leadership, decision-making and teamwork need to be redefined in order to foster enhanced employee integration. Management and personnel within an organization play a crucial role in setting the stage for change by recognising the importance and value of a culture of
Gender issues at the workplace in India

Figure 1. Transformational stages for building a culture of inclusion (Pless \& Maak, 2004).

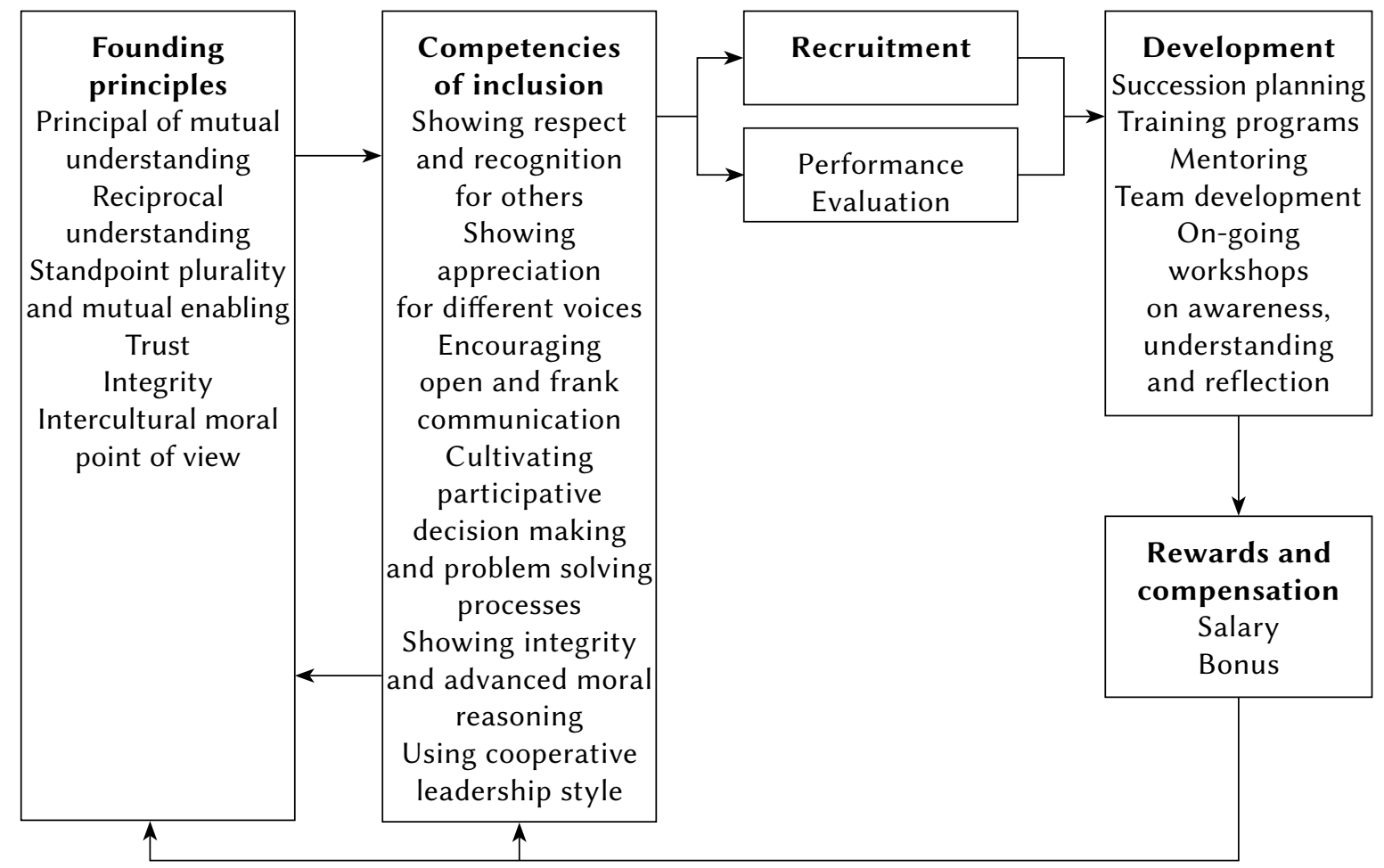

Figure 2. An integrated human relations management system to foster a culture of inclusion (Pless \& Maak, 2004). 
inclusion, by facilitating the process of defining a vision of inclusion and putting it into action by building awareness, educating and developing people, reformulating existing and introducing new personnel processes and instruments, and, last but not least, ensuring an integrated human relations approach to management that allows inclusive behaviour to be fostered and rewarded systematically at all organisational levels (Figure 2).

Suparna Jain, Gopa Bhardwaj

\section{LIMITATIONS OF THE PRESENT STUDY AND FUTURE DIRECTIONS}

1. The study has covered respondents from a mixed age group, as during qualitative data collection, many respondents, especially from the reserved category, believed that there would be a difference between generations in their view of the quota system. According to them the new generations are more educated and prepared to handle the present diversity climate. Research in future may assess this difference based on the generation to which one belongs in the perception of the diversity climate as well as the overall quota system.

2. In this study only three independent variables were included. Out of the three, two are consequent variables. More studies may be conducted including some other relevant consequent variables such as absenteeism, turnover, quality of life and so on.

3. In the study the number of participants in the four groups comprising the sample were proportionate to their true numbers in the organisations. Thus the number of participants especially in group RCW was much smaller. Future studies can take a larger sample and could be able to universalise the findings in a better way.

4. Affirmative action is prevalent in various countries, in both the east and the west. Future researchers can perform a comparative study on affirmative action and its success between the two broad cultures.

The above is not an exhaustive list of suggestions for future researchers. They may study the psychological consequences of a caste-based quota system from various arenas. In the present research only the occupational sector has been studied, but other sectors in which the quota system is prevalent such as higher education, etc., are still open to be explored.

\section{RefERENCES}

Barak, M. E. M., Cherin, D. A., \& Berkman, S. (1998). Organizational and personal dimensions in diversity climate: Ethnic and gender differences in employee perceptions. Journal of Applied Behavioral Science, 34, 82-104.
Bartoleme, F. (1972). Executives as Human Beings. Harvard Business Review, 50, 62-69.

Cable, C. (1988). Attributional processes and alienation: A typology of worker responses to unequal power relationships. Journal of Political Psychology, 9, 109-127.

Carlson, D. S., \& Perrewé, P. L. (1999). The role of social support in the stressor-strain relationship: An examination of work-family conflict. Journal of Management, 25, 513-540.

Chalofsky, N. (2003). An emerging construct of meaningful work. Human Resources Development International, 6, 69-83.

Chaudhuri, B., \& Panigrahi, A. K. (2013). Gender Bias in Indian Industries. The Journal of Industrial Statistics, 2, 108-127.

Cox, T. H., \& Beale, R. L. (1997). Developing competency to manage diversity. San Francisco: Berrett-Koehler.

Frone, M. R., Russell, M., \& Cooper, M. L. (1992). Antecedents and outcomes of work-family conflict: Testing a model of the work-family interface. Journal of Applied Psychology, 77, 65-78.

Full text of Sonia's statement on caste-based reservations. (2014, February 5). The Times of India. Retrieved from http://timesofindia.indiatimes.com/ india/Full-text-of-Sonias-statement-oncastebased-reservations/articleshow/29913719.cms

Government of India. (1950). Article 16, Section 4, Constitution of India. New Delhi: India.

Gutek, B. A., Searle, S., \& Klepa, L. (1991). Rational versus gender role explanations for work-family conflict. Journal of Applied Psychology, 76, 560-568.

Heilman, M. E. (1994). Affirmative action: Some unintended consequences for working women. Research in Organisational Behaviour, 16, 125-169.

Heilman, M. E., Lucas, J. A., \& Kaplow, S. R. (1990). Self-Derogating consequences of sex based preferential selection: The moderating role of initial self confidence. Organisational Behaviour and $\mathrm{Hu}$ man Processes, 46, 202-216.

Heilman, M. E., Simon, M. C., \& Repper, D. P. (1987). Intentionally favoured, unintentionally harmed? Impact of sex based preferential selection on self perception and self evaluation. Journal of Applied Psychology, 72, 62-68.

Henry, W. E. (1961). Conflict, age and the executive. Business Topics, 21, 15-25.

Korman, A., \& Wittig-Berman, U. (1980). A theory of career decision making. Montreal: American Psychological Convention.

Kotter, J. P. (1996). Leading Change. Boston, MA: Harvard Business School Press.

Luk, D. M., \& Shaffer, M. A. (2005). Work and family domain stressors and support: Within- and Cross-domain influences on work-family conflict. Journal of Occupational and Organisational Psychology, 78, 489-508. 
Maio, G. R., \& Esses, V. M. (1998). The social consequences of affirmative action: Deleterious effects on perception of groups. Personality and Social Psychology Bulletin, 24, 65-74.

Mandhana, N. (2012). Reservation bills hit hurdles in parliament. The New York Times. Retrieved from http://india.blogs.nytimes.com/2012/12/20/ reservations-bill-hits-hurdles-in-parliament/? php $=$ true\&_type $=$ blogs \&_r $=0$

Persson, J. (2009). The impact of a quota system on women's empowerment: A field study in west Bengal, India. (Master's Thesis, Department of Economics, University of Lund, Sweden). Retrieved from https://liveatlund.lu.se/intranets/LUSEM/ $\mathrm{NEK} / \mathrm{mfs} / \mathrm{MFS} / 191 . \mathrm{Pdf}$

Pless, N., \& Maak, T. (2004). Building an inclusive diversity culture: Principles, Processes and Practices. Journal of Business Ethics, 54, 129-147.

Rajadhyaksha, U., \& Smita, S. (2004). Tracing a timeline for work and family research in India. Economic and Political Weekly, 39, 1674-1680.

Rana, M. S. (2008). Reservations in India: Myths and Realities. New Delhi: Concept Publishing Company.

Schultz, D. (1974). Managing the middle aged manager. Business Management, 7, 8-17.

Seeman, M. (1959). On the meaning of Alienation. American Sociological Review, 24, 783-791.

Seeman, M. (1967). On the personal consequences of alienation in work. American Sociological Review, 32, 273-285.

Seeman, M. (1972). The signals of '68: alienation in pre-crisis France. American Sociological Review, 37, 385-402.

Shepard, J. M. (1972). Alienation as a process: work as a case in point. The Sociological Quarterly, 13, 161-173.

Sia, S. K. (2008). A study of perceived diversity climate by employees belonging to different social groups (Doctoral Dissertation) Retrieved from Central Reference Library, University of Delhi, India.

Supreme Court of India. (1990). Indra Sawhney and Ors. Vs. Union of India. Write Petition (Civil) No. 930. Retrieved from http://judis.nic.in/supremecourt/chejudis.asp

Tarnowieski, D. (1973). The changing success ethic. New York: The Free Press.

Twining, J. E. (1980). Alienation as a social process. The Sociological Quarterly, 21, 417-428.

Vloeberghs, D. (2002). An original and data based approach to the Work-family Balance. Equal Opportunities International, 21, 25-57.

Williams, K. J., \& Alliger, G. M. (1994). Role stressors, mood spill over and perceptions of work-family conflict in employed parents. Academy of Management Journal, 37, 837-868.

World Economic Forum. (2013). The Global Gender Gap Report. Retrieved from http://www.weforum. org/reports/global-gender-gap-report-2013 
APPENDIX A

\section{Interview schedule}

1. If you see a reserved category employee coming out of the boss's cabin in a shattered emotional state, what could be the reason according to you?

2. If you find a reserved category employee not working efficiently, what could be the reason?

Suparna Jain,

Gopa Bhardwaj

3. If you find a reserved and general category employee arguing, to whom would you find it easy to relate and whom would you feel like protecting?

4. If a reserved category employee is not included in discussions, what would be your opinion about it?

5. Is it any different for reserved and general category employees to strike a balance between work and family responsibilities?

6. If a person is not able to find fulfillment in his/her work, what could be the reason?

7. If you had a choice to choose your boss, what would be your criteria?

8. If your male boss often discussed his family life with employees, what would be your viewpoint?

9. If you noticed a co-employee (from the reserved category) often keeping to himself and not mingling with others, what could be the reason?

10. Does powerlessness lead to boredom in your work? Please illustrate with a true event. 